\title{
DA (IM)POSSIBILIDADE DE EFICÁCIA HORIZONTAL DOS DIREITOS FUNDAMENTAIS NA ESFERA INTERNACIONAL: A EFICÁCIA DOS DIREITOS FUNDAMENTAIS NAS RELAÇÕES ENTRE PARTICULARES NO SISTEMA INTERAMERICANO DE PROTEÇÃO AOS DIREITOS HUMANOS
}

\author{
Ianá Priscilla de Oliveira Silva*
}

\section{RESUMO:}

A violação de direitos previstos em tratados internacionais enseja responsabilização do Estado-parte perante os órgãos de controle desses instrumentos. O estudo visa a analisar a (in)eficácia horizontal dos direitos fundamentais no âmbito internacional. Para tanto, foi realizada uma pesquisa com um recorte teórico limitando a análise ao Sistema Interamericano de Proteção aos Direitos Humanos. Conclui-se que, não é possível acionar particulares por violações aos direitos fundamentais na esfera internacional, eles podem ser responsabilizados no âmbito doméstico com aplicação direta dos instrumentos internacionais.

Palavras-chave: Direito Internacional. Direitos Humanos. Direitos Fundamentais. Tratados de Direitos Humanos. Eficácia Horizontal.

\section{THE (IM) POSSIBILITY OF HORIZONTAL EFFICACY OF FUNDAMENTAL RIGHTS IN THE INTERNATIONAL SPHERE: THE EFFICACY OF FUNDAMENTAL RIGHTS IN RELATIONS BETWEEN PARTICULARS IN THE INTER-AMERICAN SYSTEM FOR THE PROTECTION OF HUMAN RIGHTS}

\begin{abstract}
:
The violation of rights provided for in international treaties entails accountability of the State party to the control bodies of these instruments. The study aims to analyze the horizontal (in) effectiveness of fundamental rights at the international level. To this end, a research was carried out with a theoretical focus limiting the analysis to the Inter-American System for the Protection of Human Rights. It is concluded that, it is not possible to sue individuals for violations of fundamental rights at the international level, they can be held responsible at the domestic level with direct application of international instruments.
\end{abstract}

Keywords: International Right. Human Rights. Fundamental Rights. Human Rights Treaties. Horizontal Efficacy.

\section{INTRODUÇÃO}

Um cenário de graves violações aos direitos humanos no âmbito internacional foi o que fez emergir a internacionalização dos direitos humanos, com a criação de sistemas de

\footnotetext{
* Mestranda em Direito no Programa de Pós-Graduação em Direito (Mestrado em Direito Público) da Faculdade de Direito de Alagoas (FDA), Universidade Federal de Alagoas (UFAL). Graduação em Direito - FDA/UFAL. Graduação em Serviço Social - Faculdade Tiradentes/AL. Bolsista Pós-Graduação CAPES. Contato: priscilla.iana@ hotmail.com; http://orcid.org/0000-0002-7196-4443.
}

CONPEDI LAW REVIEW | EVENTO VIRTUAL | v. 6 | n. 1 | p. 36 - 52 | JAN - DEZ | 2020 
proteção em âmbito global e regional que destinam-se a conferir aos direitos humanos uma proteção que ultrapassa a esfera doméstica de cada Estado.

É nesse sentido que são elencados, em tratados e convenções internacionais, direitos considerados essenciais à todos os seres humanos, os quais, uma vez cobertos pelo manto da proteção global e/ou regional, acabam sendo (re)introduzidos nos ordenamentos jurídicos internos de cada Estado, recebendo um tratamento especial e, em não raros casos, merecendo o destaque e especial proteção conferidos a normas constitucionais.

Assumidos pelos Estados o compromisso/dever de proteção aos direitos humanos, esses entes passam a ser passíveis de responsabilização internacional em casos de violações, devendo, portanto, assegurar os meios necessários a sua efetivação interna para todos os seus nacionais e, ainda, coibir que terceiros incidam nessas violações.

A violação de um direito previsto em tratado internacional, quando efetivada por um Estado-parte de uma Convenção Internacional, enseja sua responsabilização perante os órgãos responsáveis pelo controle desses instrumentos normativos, mas o que ocorre quando o que se está em jogo são violações de direitos fundamentais em relações das quais o Estado não é parte? Pode um particular ser responsabilizado diretamente pela violação de direitos fundamentais tutelados por instrumentos internacionais dos quais seu Estado é signatário?

Para responder a essas questões é preciso retomar conceitos basilares acerca da temática da eficácia horizontal dos direitos fundamentais, de modo a se analisar se é ou não possível exigir que em relações entre particulares, nas quais o Estado não é parte, que se observem os direitos fundamentais e, ainda, responsabilizar particulares pelas violações que venham a cometer, tanto no âmbito do direito interno quanto na proteção internacional conferida a esses direitos.

Diante disso, o presente trabalho se propõe a analisar o instituto da eficácia horizontal dos direitos fundamentais para verificar se é ou não possível que ela ocorra a nível internacional. Para tanto, foi realizada uma pesquisa bibliográfica a respeito da temática, partindo-se de um recorte teórico limitando a análise ao Sistema Interamericano de Proteção aos Direitos Humanos.

Para isso, e sem pretensão de esgotar a temática em análise, parte-se de uma discussão acerca da existência das diferenças conceituais em relação a Direitos Humanos e Direitos Fundamentais, para que se tenham em mente quais os conceitos adotados ao longo do estudo e o alcance da responsabilidade a que este se refere. Ainda, serão apresentados, de 
forma sucinta a eficácia dos direitos fundamentais, vertical e horizontal, de modo a delimitar o recorte teórico proposto. Por fim, ser analisada a eficácia horizontal das normas de direitos fundamentais fundadas em tratados internacionais no Sistema Interamericano de Proteção aos Direitos Humanos.

\section{DIREITOS HUMANOS E DIREITOS FUNDAMENTAIS}

Dentre os conceitos que se mostram essenciais para o estudo aqui proposto, inicia-se a discussão a partir da ideia do que são direitos humanos e direitos fundamentais.

A esse respeito, podem ser encontrados na doutrina pátria autores que defendem posicionamentos distintos acerca da existência de uma diferença basilar entre ambos os conceitos.

Nesse sentido, pode-se resumir essas posições da seguinte forma: a) autores que utilizam as expressões direitos humanos e direitos fundamentais como sinônimos, de modo que ambas fariam referência à mesma gama de direitos, podendo ser utilizada uma ou outra expressão, sem qualquer distinção e; b) autores que apontam distinções entre as expressões, de modo que se tratariam de direitos distintos ou, ainda, da mesma gama de direitos, mas que ocupariam uma posição distinta quando analisados á luz do direito interno ou do direito internacional, posição adotada no presente estudo.

Em relação ao primeiro posicionamento, alhures indicado, é de se dizer que utilizar essas duas expressões como sinônimo se torna possível apenas para fins didáticos, desde que se deixe claro que se tratam de expressões que compreendem universos distintos de direitos, seja pelos próprios direitos abarcados ou pelo âmbito de proteção a que cada um se refere.

A título de exemplo, pode ser mencionado um Estado que tenha ratificado a Convenção Americana de Direitos Humanos, a qual prevê, em seu artigo $1^{\circ}$, um dever geral de respeito aos direitos por ela previstos, sem qualquer discriminação, inclusive por motivo de sexo. Agora, consideremos que esse mesmo Estado, em sua Constituição, não assegure a igualdade entre homens e mulheres, pelo contrário, assegure direitos apenas aos homens, colocando as mulheres como seres humanos de segunda classe. Nesse caso, então, estaríamos diante de uma norma de direitos humanos, prevista e tutelada por uma convenção internacional, mas que não recebeu proteção constitucional pelo direito interno do Estado signatário, não alcançando, portanto, o status de direito fundamental, o que, destaque-se, não 
desobriga o Estado signatário de sua observância e da responsabilização pelo seu descumprimento.

A esse respeito, Aragão (2011, p. 259-260) aponta que "São utilizadas diversas expressões tais como direitos naturais, direitos humanos, direitos do homem, direitos individuais, direitos públicos subjetivos, liberdades fundamentais [...]”, entre outros, destacando que a existência de tão vasta quantidade de nomenclaturas para se referir aos direitos fundamentais tornariam difícil a sua conceituação definitiva.

Também Silva (2005, p. 178), analisando a questão da definição adequada de direitos humanos e fundamentais, utiliza-se da expressão "Direitos Fundamentais do Homem", a qual indica ser a mais adequada, pois:

No qualitativo fundamentais acha-se a indicação de que se trata de situações jurídicas sem as quais a pessoa humana não se realiza, não convive e, às vezes, nem mesmo sobrevive; fundamentais do homem no sentido de que a todos, por igual, devem ser, não apenas formalmente reconhecidos, mas concreta e materialmente efetivados. Do homem, não como o macho da espécie, mas no sentido de pessoa humana. Direitos fundamentais do homem significa direitos fundamentais da pessoa humana ou direitos fundamentais (SILVA, 2005, p. 178).

No entanto, como bem aponta Sarlet (2012, p. 18), embora esses conceitos sejam utilizados como sinônimos, a expressão direitos fundamentais se refere a direitos humanos positivados constitucionalmente por um Estado, enquanto direitos humanos tem relação com documentos internacionais, não se restringindo a um Estado específico, visando a uma aplicabilidade universal, com abrangência para além dos Estados.

Também Alexandrino (2011, p. 2) é adepto dessa corrente, asseverando que a distinção entre direitos humanos e direitos fundamentais é de máxima importância, visto que se tratam de: (1) realidades diferentes, (2) contextos de partida diferentes e (3) regras de interpretação diferentes. Dessa forma, esclarecedores os apontamentos do autor, os quais transcreve-se a seguir:

A distinção entre essas realidades, direitos fundamentais e direitos humanos, tenhoa feito assentar nos seguintes cinco elementos: (i) os direitos humanos podem ser direitos puramente morais, ao passo que os direitos fundamentais são sempre direitos jurídicos (há neles necessariamente uma conexão com o Direito positivo); (ii) os direitos humanos não estão necessariamente positivados, ao passo que os direitos fundamentais são direitos previstos na Constituição (podendo estes conceber-se ainda como resultado do processo jurídico de institucionalização daqueles), estando necessariamente configurados e limitados pela Constituição (sistema de direitos fundamentais); (iii) os direitos humanos apresentam uma pretensão de vinculatividade universal, ao passo que os direitos fundamentais vinculam sobretudo (ou apenas) o Estado (os poderes públicos), no âmbito de uma ordem jurídica concreta, situada no espaço e no tempo; (iv) os direitos humanos são, em regra, direitos abstractos, ao passo que os direitos fundamentais incorporam tradicionalmente garantias jurídicas concretas e delimitadas, imediatamente 


\section{DA (IM)POSSIBILIDADE DE EFICÁCIA HORIZONTAL DOS DIREITOS FUNDAMENTAIS NA ESFERA INTERNACIONAL: A EFICÁCIA DOS DIREITOS FUNDAMENTAIS NAS RELAÇÕES ENTRE PARTICULARES NO SISTEMA INTERAMERICANO DE PROTEÇÃO AOS DIREITOS HUMANOS}

accionáveis pelos interessados; (v) nada impede que os direitos humanos possam, em certos casos e para certos efeitos, ser concebidos como fins ou como programas morais de reforma ou de ação política, ao passo que os direitos fundamentais necessitam sempre de determinados mecanismos de garantia jurisdicional (ALEXANDRINO, 2011, p. 3).

Como visto, existem inúmeras distinções entre direitos humanos e direitos fundamentais, seja em relação à natureza desses direitos, à questão da positivação constitucional, ao alcance (âmbito de um Estado determinado ou universal) ou à forma como esses direitos são garantidos na prática.

Tratando sobre direitos humanos, Comparato (1998, p. 19) aponta um pleonasmo no uso da expressão direitos humanos, mas entende que é justificado, visto que direitos humanos são comportamentos que tem fundamento na participação do gênero humano. Ainda, o referido autor indica que o conceito de direitos humanos pode ser encontrado na Declaração Universal dos Direitos do Homem, a qual destaca que todos fazem jus aos direitos e liberdades proclamados pelo referido texto normativo, não devendo ser consideradas, como pretexto para afastamento de sua efetivação, qualquer distinção, inclusive as que se referem a nacionalidade (COMPARATO, p. 19).

Cademartori e Grubba (2012, p. 716) apontam que os direitos humanos são processos de lutas pelo acesso universal a bens materiais e imateriais, a exemplo da vida digna.

Em relação aos direitos fundamentais, essencialmente, estes podem ser conceituados como sendo direitos inerentes à condição humana, mas que estão previstos em um ordenamento jurídico específico.

Relacionando, ainda, um e outro direito, Sarlet (2012, p. 6) afirma que, embora direitos humanos sejam aqueles que possuem tutela internacional e direitos fundamentais os que encontram-se positivados em ordenamentos jurídicos estatais, a positivação de direitos fundamentais não exclui os direitos humanos previstos em tratados internacionais, tendo em vista que, a exemplo do que ocorre no Brasil, a existência de direitos e garantias expressos na Constituição não exclui a existência de outros direitos decorrentes, dentre outros, de tratados internacionais dos quais o Brasil faça parte.

Ao tratar sobre direitos fundamentais, Alexy (2015, p. 520-522) esclarece que a fundamentalidade dos direitos resulta da conjunção de sua fundamentalidade formal, a qual “[...] decorre da sua posição no ápice da estrutura escalonada do ordenamento jurídico, como direitos que vinculam diretamente o legislador, o Poder Executivo e o Judiciário", e da fundamentalidade substancial, que se refere à utilização de direitos fundamentais para a tomada de decisões "[...] sobre a estrutura básica do Estado e da Sociedade". 
Ainda, a respeito dos Direitos Fundamentais na Constituição Federal de 1988, importante a fala de Sarlet, conforme segue:

\begin{abstract}
A Constituição Federal de 05.10.1988 agasalhou, no seu Título II (Dos Direitos e Garantias Fundamentais) um extenso e diferenciado rol de posições jurídicas expressamente designadas de fundamentais, logo após ter enunciado os princípios e objetivos fundamentais, dentre os quais desponta a dignidade da pessoa humana, expressamente guindada à condição de fundamento da República Federativa do Brasil. Sem que se possa aqui adentrar a discussão em torno da qualidade "jusfundamental" de todas as posições jurídicas consagradas (mais de uma centena) no Título II, comunga-se da tendência majoritária no sentido de reconhecer que todos os direitos e garantias lá positivados são fundamentais e que em favor da opção expressa do Constituinte milita uma presunção em prol da fundamentalidade tanto dos assim designados direitos e deveres individuais e coletivos, quanto dos direitos sociais (incluindo extenso elenco de direitos dos trabalhadores), dos direitos de nacionalidade e dos direitos políticos (SARTLET, 2012, p. 5-6).
\end{abstract}

Como dito, será adotada no presente estudo a posição segundo a qual direitos humanos e direitos fundamentais são distintos, mas guardam uma relação por meio da qual, embora não possam ser confundidos, são os direitos humanos que representam o fundamento humanista dos direitos fundamentais/positivados, podendo os direitos humanos ser positivados para que se assegure juridicamente sua efetividade, seja por meio dos tratados internacionais ou diretamente no ordenamento jurídico interno de um Estado. ${ }^{1}$

Então, havendo essa diferenciação entre direitos humanos e direitos fundamentais, mas havendo, também, uma relação entre ambos os conceitos, é possível concluir que um mesmo direito pode ser entendido como direito humano, contando, portanto, com proteção internacional, e, ao mesmo tempo, como direito fundamental, sendo assim enquadrado pelo ordenamento jurídico de um Estado específico. Sendo assim, a depender do direito a que estamos nos referindo, podemos estar diante de um direito humano e fundamental.

A forma como se dá a eficácia desses direitos será tratada a seguir.

\title{
3 EFICÁCIA DOS DIREITOS FUNDAMENTAIS
}

\footnotetext{
${ }^{1}$ A esse respeito, veja-se a fala de Cademartori e Grubba, ao apresentarem os pensamentos de Joaquin Herrera Flores e Luigi Ferrajoli: "Do exposto, pode-se dizer que, entre Joaquín Herrera Flores e Luigi Ferrajoli, acima das diferenças, coexistem pontos de identidade em seus pensamentos. Acima da identidade, o respeito pelas diferenças. Respectivamente, um se apresenta como filósofo do direito, que cria sua própria teoria. O outro, um teórico do direito que expõe sua filosofia. Ambos preocupados com o presente e o futuro da humanidade. Herrera Flores escreve primordialmente sobre direitos humanos, vale dizer, sob um enfoque universalista de direitos afirmados politicamente a partir de lutas sociais. Ferrajoli se preocupa principalmente com os direitos fundamentais e a realização de sua garantia, porém conquanto pertencentes ao fenômeno dos direitos do humano, em nível global, pois conforme já salientado, os direitos fundamentais são a versão positivada e dogmática dos primeiros no âmbito dos diversos ordenamentos jurídicos que os acolhem." (CADEMARTORI; BRUBBA, 2012, p. 720).

CONPEDI LAW REVIEW | EVENTO VIRTUAL | v. 6 | n. 1 | p. 36 - 52 | JAN - DEZ | 2020 
DA (IM)POSSIBILIDADE DE EFICÁCIA HORIZONTAL DOS DIREITOS FUNDAMENTAIS NA ESFERA INTERNACIONAL: A EFICÁCIA DOS DIREITOS FUNDAMENTAIS NAS RELAÇÕES ENTRE PARTICULARES NO SISTEMA INTERAMERICANO DE PROTEÇÃO AOS DIREITOS HUMANOS

Eficácia, nas palavras de Soibelman (2006, p. 1764) é um termo “[...] derivado do latim efficacia, de efficax (que tem virtude, que tem propriedade, que chega ao fim), compreende-se como a força ou poder que possa ter um ato ou um fato, para produzir os desejados efeitos".

Em síntese, eficácia é o poder que uma norma tem para produzir efeitos, enquanto efetividade se relaciona aos efeitos sociais da norma, ou seja, significa dizer que determinada norma está concretamente produzindo o efeito de regulamentar a vida social (MARRAFON; ROBI FILHO, 2014, p. 284).

Alvarenga (2008, p. 209), apresentando a teoria de José Afonso da Silva, esclarece que a existe uma relação entre aplicabilidade e eficácia das normas constitucionais, a qual pode se apresentar de três maneiras: (i) aplicabilidade imediata e eficácia plena, (ii) aplicabilidade imediata e eficácia contida e (iii) aplicabilidade mediata ou eficácia limitada, as quais representam, respectivamente, que a norma não depende de legislação complementar para produzir todos os seus efeitos, a norma foi suficientemente regulada pelo constituinte originário, mas pode ter seus efeitos limitados pelo legislador ordinário e, por fim, normas que somente passarão a produzir seus efeitos após atuação do legislador ordinário (ALVARENGA, 2008, p. 209).

Segundo afirmam Rocha (1997, p. 13) e Reissenger (2006, p. 1765-1766), a própria Constituição Federal de 1988, em seu artigo $5^{\circ}, \S 1^{\text {o }}{ }^{2}$ dispõe que as normas constitucionais de direitos fundamentais são normas de aplicação imediata, mas sua eficácia plena não pode ser constatada tão facilmente quanto essa imediaticidade de sua aplicação.

Tratando-se da eficácia dos tratados internacionais de direitos humanos, Moraes (2017, p. 93) esclarece que a Constituição brasileira seguiu a tendência internacional quando adotou o procedimento previsto no artigo $5^{\circ}, \S 3^{\circ}$, prevendo a possibilidade de atribuição de status constitucional aos tratados internacionais de direitos humanos e, ainda, ao "[...] ao permitir o deslocamento de competência nas hipóteses de grave violação a esses direitos".

A fala do supracitado autor coaduna com os esclarecimentos feitos por Sarlet (2012, p. 21), segundo o qual a eficácia jurídica e social dos direitos humanos e, consequentemente, dos tratados internacionais de direitos humanos pelos quais são tutelados, depende da recepção pelo Estado e da forma como essas normas são recepcionadas, ou seja, do status jurídico a elas atribuído pelo ordenamento jurídico do Estado, pois, segundo o autor, lhes

2 “Art. $5^{\circ}, \S 3^{\circ}$ - As normas definidoras dos direitos e garantias fundamentais têm aplicação imediata". CONPEDI LAW REVIEW | EVENTO VIRTUAL | v. 6 | n. 1 | p. 36 - 52 | JAN - DEZ | 2020 
faltaria cogência. Nesse sentido, continua, a efetivação dos direitos humanos depende da vontade dos Estados (SARLET, 2012, p. 21). E conclui o autor:

Em suma, reputa-se acertada a ideia de que os direitos humanos, enquanto carecem do caráter da fundamentalidade formal próprio dos direitos fundamentais [...] não lograrão atingir sua plena eficácia e efetividade, o que não significa dizer que em muitos casos não a tenham (SARLET, 2012, p. 21).

Ou seja, pelo entendimento do autor, é apenas a partir da análise do status atribuído pelo ordenamento jurídico do Estado ao tratado internacional de direito humano que poderá ser verificada sua eficácia e efetividade. No entanto, ainda em sua fala, Sarlet (2012, p. 21) afirma que não se deve perder de vista a “[...] evolução progressiva na eficácia dos mecanismos jurídicos internacionais de controle [...]” (2012, p. 21).

Dessa fala do autor, pode-se extrair que também por meio dos mecanismos de controle instituídos pelos tratados internacionais de direitos humanos é possível buscar sua efetividade e eficácia plenas.

Do ponto de vista da eficácia do tratado internacional de direitos humanos objeto do presente estudo, qual seja, a Convenção Americana de Direitos Humanos, percebe-se que, ela possui o poder de produzir efeitos, tanto no âmbito interno - tendo sido reconhecido o status supralegal do Tratado pela jurisprudência pátria, quanto no âmbito internacional - com o funcionamento dos mecanismos e órgãos de controle da convenção.

Como visto, tudo o que foi tratado até aqui diz respeito à eficácia vertical dos direitos fundamentais e dos direitos humanos, nas relações em que o Estado figure como parte juntamente com um particular. Mas, o que acontece quando a relação se dá entre particulares? A que tipo de eficácia nos referimos? Trata-se da mesma modalidade e funcionamento aplicados às relações que incluem o Estado? Isso é o que veremos a seguir.

A esse respeito, resumem Magalhães e Dutra (2019) dá-se o nome de eficácia horizontal dos direitos fundamentais quando se está diante da eficácia de direitos fundamentais em relação horizontalizadas, nas quais, não há relação de subordinação, ou seja, nas relações entre particulares, que são entendidos como indivíduos juridicamente iguais. Criticando essa nomenclatura, Rodrigues e Leal (2018, p. 1-42) aduzem que a ideia de horizontalidade remete à igualdade e ao equilíbrio, mas não seria esse o caso das relações entre os particulares, visto que, “[...] muitas vezes um dos polos tenta impor sua força para sujeitar a parte mais fraca, causando um desnível, tal qual existe na relação vertical entre o 


\section{DA (IM)POSSIBILIDADE DE EFICÁCIA HORIZONTAL DOS DIREITOS FUNDAMENTAIS NA ESFERA INTERNACIONAL: A EFICÁCIA DOS DIREITOS FUNDAMENTAIS NAS RELAÇÕES ENTRE PARTICULARES NO SISTEMA INTERAMERICANO DE PROTEÇÃO AOS DIREITOS HUMANOS}

indivíduo e o Estado", sendo mais adequada a expressão "eficácia dos direitos fundamentais nas relações privadas".

Realizando um resgate histórico das teorias sobre a temática, Zamorano (2014) indica, inicialmente, que, em primeiro lugar, existe um posicionamento com pouco prestígio, a qual denomina de Teoria da Ineficácia Horizontal, desenvolvida pela Suprema Corte dos Estados Unidos, a qual nega a possibilidade de produção de efeitos dos direitos fundamentais nas relações entre particulares. A esse respeito, Rodrigues e Leal (2018, p. 1-42) esclarecem que a teoria da State Action tem como fundamento principal a preservação da autonomia privada. Segundo os referidos autores, ainda, a jurisprudência norte americana tem estendido essa teoria, formando o que se denomina de public function theory, de modo a estender a observância aos direitos fundamentais aos particulares que desempenhem funções típicas do Poder Público (RODRIGUES, 2018, p. 1-42).

Além dessa teoria, a supracitada autora menciona outras três teses a respeito da eficácia horizontal dos direitos fundamentais:

Tese da eficácia mediata ou indireta - A tese da eficácia horizontal indireta ou mediata dos direitos fundamentais tem como ponto de partida o reconhecimento de um direito geral de liberdade, que propicia aos participantes de uma relação privada a possibilidade de afastarem as disposições de direitos fundamentais, sem a qual a liberdade contratual restaria comprometida. [...]. Desse modo, para os adeptos dessa concepção, a força jurídica dos preceitos constitucionais somente se afirmaria em relação aos particulares, por meio dos princípios e normas de direito privado. Isso ocorreria através de normas de direito privado - ainda que editadas em razão do dever de proteção do Estado.

Tese da eficácia imediata ou direta - Segundo seus defensores, os direitos fundamentais, tal como previstos no texto constitucional, já trazem condições de plena aplicabilidade nas relações entre particulares, dispensando qualquer tipo de mediação infraconstitucional. Nesse sentido, com base da perspectiva da máxima efetividade, a Constituição - com seu rol de direitos fundamentais - deveria ser aplicada diretamente nas relações entre particulares.

Teoria dos Deveres de Proteção - Essa teoria sustenta não estarem os sujeitos de Direito Privado vinculados diretamente aos direitos fundamentais, como estão os Poderes Públicos. Todavia, o Estado, tanto ao editar normas como ao prestar a jurisdição, está obrigado não apenas a abster-se de violar os direitos fundamentais, como também a protegê-los diante das lesões e ameaças provenientes dos particulares. Por conseguinte, essa teoria diferencia-se da aplicabilidade indireta justamente por impor ao Estado o dever de vigilância (ZAMORANO, 2014).

Como visto, segundo a referida autora, tem-se duas teses com posições diametralmente opostas, uma que nega completamente a aplicabilidade dos direitos fundamentais às relações entre particulares e outra que defende sua aplicabilidade imediata, sem necessidade de edição de nenhuma norma secundária. Entre essas teorias, encontram-se as outras duas teses, segundo as quais há a possibilidade de produção de efeitos dos direitos 
fundamentais nas relações entre particulares, no entanto, é necessária uma atuação do legislador ou do Estado para que isso ocorra.

Outros autores também mencionam as supracitadas teses. Nesse sentido, Gorzoni (2007) trata das duas teses, quais sejam: a) Eficácia Direta ou Imediata e; b) Eficácia Indireta ou Mediata, as quais podem ser definidas, respectivamente, de forma sucinta, como a aplicabilidade imediata, com efeitos absolutos dos direitos fundamentais entre os particulares ou a eficácia dos direitos fundamentais nas relações entre particulares apenas após a edição de normas de direito privado.

Trazendo elementos que agregam significado aos conceitos já apresentados, Viegas e Nascimento (2019), assevera que "[...] eficácia indireta ou mediata significa dizer que, os direitos fundamentais não são aplicados como direitos subjetivos, e para serem acionados, deverão ser sob o comando da Constituição, devido ao caráter constitucional da autonomia privada", de modo a possibilitar, inclusive, que o particular renuncie a esses direitos na esfera das relações particulares.

Problematizando a questão da eficácia horizontal dos direitos fundamentais, a qual denomina de "eficácia dos direitos fundamentais nas relações interprivadas", Sarlet (2012) diferencia tipos específicos de direitos que tem como destinatário ou sujeito passivo, direto e imediato, o poder público, de modo que, nesse caso, não haveria controvérsia quanto à sua eficácia. Por outro lado, também segundo o autor, existem direitos fundamentais que se dirigem diretamente aos particulares (ou também a eles), citando como exemplos o direito à indenização por dano moral ou material, inviolabilidade de domicílio, sigilo das correspondências e comunicações telegráficas e telefônicas, direitos dos trabalhadores (dirigidos aos empregadores).

Continuando sua análise, o supracitado autor afirma que a forma pela qual se apresenta o Estado, Liberal ou Social, vai dar indicativos da forma como se dará a eficácia dos direitos fundamentais. Sendo o Estado Liberal, parte-se da ideia de direitos de defesa, por meio dos quais os particulares buscam refrear as ações estatais ou proteger-se contra ataques praticados pelo Estado contra seus direitos. Por outro lado, no Estado Social, a liberdade individual carece de proteção não apenas contra arbítrios do Estado, mas também contra violações levadas a cabo por particulares, em especial, por aqueles que detém certo poderio econômico e social (SARLET, 2012). 
Para Dimoulis e Martins (2014), a tese aplicada no ordenamento jurídico brasileiro é a da eficácia mediata ou indireta, de modo para que se alcance a eficácia dos direitos fundamentais nas relações entre particulares há a necessidade de intermediação por meio de normas infraconstitucionais, conforme se observa a seguir:

\begin{abstract}
Em resumo, no ordenamento jurídico brasileiro, vale como regra geral que destinatário dos deveres que correspondem aos direitos fundamentais é o Estado, tanto no sentido do dever de abstenção como no sentido do dever de ação mediante prestações. Os particulares devem respeitar os direitos fundamentais na exata medida em que estes forem concretizados por leis infraconstitucionais (o direito fundamental à vida corresponde à punição do homicídio etc.). No mais, os direitos fundamentais desenvolvem como aludido um "efeito de irradiação" na interpretação da legislação comum, principalmente de cláusulas gerais.
\end{abstract}

Dessa forma, dialogando com a questão da eficácia de direitos fundamentais tutelados por diplomas internacionais dos quais o Brasil seja signatário, segundo a explicação apresentada pelo supracitado autor, a eficácia horizontal dos direitos humanos previstos em instrumentos internacionais, no Brasil, só poderia ocorrer por meio da internalização desses direitos no ordenamento jurídico doméstico, por meio não apenas de sua introdução no rol de direitos fundamentais previstos na Constituição Federal, mas também pela edição de normas infraconstitucionais que tratem especificamente de cada um desses direitos.

No entanto, existem doutrinadores que asseveram a possibilidade e, ainda, a previsão expressa de eficácia direta e imediata dos direitos fundamentais de tratados internacionais para relações entre particulares, como será exposto a seguir.

\title{
4 EFICÁCIA HORIZONTAL DOS DIREITOS FUNDAMENTAIS NA ESFERA INTERNACIONAL E O SISTEMA INTERAMERICANO DE PROTEÇÃO AOS DIREITOS HUMANOS
}

O presente estudo foi iniciado visando à responder aos seguintes questionamentos: pode um particular ser responsabilizado diretamente pela violação de direitos fundamentais tutelado por instrumentos internacionais dos quais seu Estado é signatário?

Como visto, existem teorias que apontam no sentido de que os direitos fundamentais, quando encarados diretamente dos instrumentos internacionais que lhes tutelam, teriam sua eficácia limitada às relações em que o Estado figura no pólo passivo, ou seja, só seriam exigíveis do Estado e somente este poderia ser responsabilizado por possíveis violações; ainda, teses que apontam no sentido de que haveriam possibilidade de eficácia dos direitos fundamentais quando internalizados se, e somente se, o Poder Público atuasse por meio da 
elaboração de legislação interna específica, por meio da qual obrigasse os particulares a respeitarem os direitos fundamentais, mesmo nas relações unicamente entre particulares; por fim, ainda, existem teses no sentido de que a eficácia horizontal dos direitos fundamentais seria plena, sendo desnecessária a elaboração de quaisquer normas infraconstitucionais para que produzam seus efeitos nas relações havidas entre particulares.

Diante desses posicionamentos tão distintos, é preciso esclarecer, logo de início, que tratados internacionais de proteção aos direitos humanos, direitos esses que, em sua maioria são internalizados pelos Estados signatários dos tratados internacionais e, no direito interno, passam a assumir o caráter de direitos fundamentais, têm como sujeitos passivos, quando nos referimos à responsabilização internacional, apenas os Estados-partes, de modo que, não é possível se falar, salvo casos de responsabilização criminal internacional em casos e tratados específicos sobre essa temática, em responsabilização internacional de particulares por violação aos direitos fundamentais perante órgãos internacionais.

No entanto, isso não significa dizer que particulares são imunes a qualquer tipo de responsabilização, muito pelo contrário.

Conforme esclarece Daniel Sarmento (2010), é dominante o entendimento doutrinário de que os tratados internacionais de proteção aos direitos humanos, no âmbito do Sistema Global de Proteção aos Direitos Humanos geram para os Estados signatários o dever de proteger os direitos por eles tutelados, inclusive contra ameaças e violações perpetradas por particulares. Nesse sentido, afirma o autor:

Esta foi a posição claramente adotada pelo Comitê de Direitos Humanos da ONU, que em vários relatórios e comentários gerais que divulgou, demarcou com clareza a necessidade de os Estados adotarem as medidas necessárias para a garantia dos direitos fundamentais nas relações entre particulares. Portanto, reconhece-se a incidência dos direitos humanos previstos em tratados internacionais na seara das relações privadas, apesar da impossibilidade de utilização direta dos instrumentos do Direito Internacional contra indivíduos ou empresas. Não obstante, embora no plano dos órgãos internacionais de fiscalização e monitoramento ainda não seja possível agir diretamente contra particulares, nada impede que, no âmbito da jurisdição doméstica de cada Estado signatário destes tratados e convenções internacionais, o Judiciário aplique diretamente os direitos humanos neles previstos às relações privadas, impedindo e coibindo as infrações perpetradas por entidades não estatais (SARMENTO, 2010).

Da fala do autor se conclui que, quando os organismos internacionais prevêem expressamente que os Estados têm o dever de proteger os direitos humanos contra ameaças e violações perpetradas por particulares, isso significa dizer que pode haver violação de direitos humanos e, em consequência, de direitos fundamentais nas relações em que figurem apenas particulares, ou seja, nas relações privadas. No entanto, esclarece ainda o supracitado autor, CONPEDI LAW REVIEW | EVENTO VIRTUAL | v. 6 | n. 1 | p. 36 - 52 | JAN - DEZ | 2020 
não é possível acionar diretamente os mecanismos de proteção internacional para sancionar um particular que pratique as condutas consideradas violadores em face de outro particular, tendo em vista a especificidade da seara processual internacional, a qual não legitima as relações eminentemente particulares para serem acionadas no âmbito dos órgãos internacionais de proteção. Deixa claro, ainda, que nada impede que o Estado tutele essas relações, com base nesses instrumentos internacionais, em sua jurisdição interna, com aplicação direta dos direitos neles previstos.

Destaca ainda o autor que "A grande dificuldade inerente ao reconhecimento da vinculação dos particulares aos direitos fundamentais no plano da jurisdição supracional dos direitos humanos é de natureza processual” (SARMENTO, 2010), isso porque, como dito, são permitidas perante os órgãos de proteção internacional aos direitos humanos, no âmbito global ou regional, apenas demandas contra Estados, vedadas demandas contra particulares, sem no entanto, se excluir do âmbito de vinculação desses tratados as pessoas e entidades privadas, ou seja, embora não possam ser internacionalmente demandadas, essas pessoas estão vinculadas aos tratados e devem observar as garantias e proteção neles previstos.

Tratando especificamente do Sistema Interamericano de Proteção aos Direitos Humanos, Daniel Sarmento é esclarecedor ao resumir a situação da eficácia horizontal dos direitos humanos, o que pode ser estendido aos direitos fundamentais que tenham os instrumentos desse sistema de proteção como fundamento, conforme segue:

No âmbito do sistema americano de proteção de direitos humanos, o debate
doutrinário sobre a questão é praticamente inexistente. Sem embargo, o art. $1^{\circ}$ do
Pacto parece consagrar, de forma cristalina, o dever do Estado não apenas de abster-
se de violentar os direitos que consagra, mas também de protegê-los de agressões
provenientes de terceiros. Reza o referido artigo que "os Estados-partes nesta
Convenção comprometem-se a respeitar os direitos e liberdades nela reconhecidos e
a garantir seu livre e pleno exercício a toda pessoa sujeita à sua jurisdição [...]".
Ademais há direitos reconhecidos na Convenção Interamericana em que a
vinculação dos particulares é inexorável, como a proibição de escravidão ou
servidão (art. $6^{\circ}$ ), e o direito de retificação ou de resposta (art. 14). Sem falar na
previsão expressa de eficácia horizontal dos direitos da criança, no art. 19, segundo
o qual "toda criança terá direito às medidas de proteção que a sua condição de menor
requer, por parte da sua família, da sociedade e do Estado". E, finalmente, há
deveres para os indivíduos, ao estabelecer que "toda pessoa tem deveres para com a
família, a comunidade e a humanidade". Neste contexto, entendemos que a eficácia
do Pacto de San José nas relaçães privadas é inequívoca, apesar da dificuldade
processual da sua tutela no âmbito da jurisdição internacional, decorrente da
impossibilidade de se acionarem entidades não estatais perante a Corte ou a
Comissão Interamericana de Direitos Humanos (SARMENTO, 2010). É de se entender, portanto, que, primeiro, não se tem um debate doutrinário muito desenvolvido sobre essa temática e, de fato, quando da realização de pesquisas doutrinárias na busca por fontes especificas sobre essa discussão, poucos são os livros e artigos que tratam da 
temática, sendo encontradas discussões mais amplas sobre eficácia horizontal dos direitos fundamentais, mas sem adentrar no mérito da eficácia horizontal fundada em instrumentos internacionais de proteção aos direitos humanos.

Ainda, da fala do autor, se extrai que existe a previsão expressa no principal instrumento normativo do Sistema Interamericano de Proteção aos Direitos Humanos que se refere à eficácia horizontal dos direitos nele dispostos, de modo que, é de se concluir, respondendo ao questionamento inicialmente feito nesse estudo, que sim, um particular pode ser responsabilizado diretamente pela violação de direitos fundamentais tutelados por instrumentos internacionais dos quais seu Estado é signatário, embora isso não possa ocorrer perante os órgãos internacionais de proteção aos direitos humanos, visto que nestes órgãos as relações particulares não estão abrangidas para fins de demandas abarcadas pela jurisdição internacional.

Encerrando nossa discussão, é de se mencionar, ainda, os apontamentos de Setti e Lima (2020), segundo os quais embora as violações aos direitos humanos e, consequentemente, a direitos internalizados pelos Estados como direitos fundamentais, não sejam passíveis de responsabilização internacional dos particulares perante os órgãos internacionais de proteção, ensejam responsabilização direta dos Estados, não pela perpetuação direta das condutas violadoras dos direitos nas relações particulares (violação do direito a vida por um particular, por exemplo), mas pela violação de seu dever de assegurar a proteção aos direitos tutelados, prevenir ou remediar as violações perpetradas por parte dos particulares sujeitos à sua jurisdição. Tal atitude, de responsabilização estatal pela violação cometida por particulares, é justificada, segundo os autores, em razão do próprio caráter da proteção internacional aos direitos humanos, pois, segundo eles, caso houvesse a possibilidade de responsabilização direta dos particulares, isso acabaria por desvirtuar a base internacional da proteção aos direitos humanos, centrada na responsabilização estatal pela garantia e proteção a esses direitos.

\section{CONCLUSÃO}

Como visto, direitos humanos e direitos fundamentais não são sinônimos. Enquanto direitos fundamentais se referem a direitos humanos positivados constitucionalmente por um 


\section{DA (IM)POSSIBILIDADE DE EFICÁCIA HORIZONTAL DOS DIREITOS FUNDAMENTAIS NA ESFERA INTERNACIONAL: A EFICÁCIA DOS DIREITOS FUNDAMENTAIS NAS RELAÇÕES ENTRE PARTICULARES NO SISTEMA INTERAMERICANO DE PROTEÇÃO AOS DIREITOS HUMANOS}

Estado, direitos humanos têm relação com documentos internacionais, não se restringindo a um Estado específico, visando a uma aplicabilidade universal.

Existem teorias que apontam no sentido de que os direitos fundamentais, quando encarados diretamente dos instrumentos internacionais que lhes tutelam, teriam sua eficácia limitada às relações em que o Estado figura no pólo passivo, ou seja, só seriam exigíveis do Estado e somente este poderia ser responsabilizado por possíveis violações; ainda, teses que apontam no sentido de que haveriam possibilidade de eficácia dos direitos fundamentais quando internalizados se, e somente se, o Poder Público atuasse por meio da elaboração de legislação interna específica, por meio da qual obrigasse os particulares a respeitarem os direitos fundamentais, mesmo nas relações unicamente entre particulares; por fim, ainda, existem teses no sentido de que a eficácia horizontal dos direitos fundamentais seria plena, sendo desnecessária a elaboração de quaisquer normas infraconstitucionais para que produzam seus efeitos nas relações havidas entre particulares.

Por meio do estudo aqui realizado foi possível concluir que a eficácia horizontal dos direitos fundamentais possui fundamento expresso e tutela por parte dos instrumentos internacionais de proteção aos direitos humanos de modo que, no âmbito do Sistema Interamericano de Proteção aos Direitos Humanos, embora não seja possível acionar particulares por violações aos direitos fundamentais na esfera internacional, esses particulares são obrigados expressamente à observância das normas de direitos fundamentais, podendo ser responsabilizados no âmbito doméstico com a aplicação direta dos instrumentos internacionais dos quais seu Estado seja signatário, reservando-se a responsabilização internacional perante órgãos internacionais de proteção aos direitos humanos exclusivamente aos Estados.

\section{REFERÊNCIAS}

ALEXANDRINO, José Melo. Hermenêutica dos Direitos Humanos. In: CURSO TUTELA DOS DIREITOS HUMANOS E FUNDAMENTAIS, Faculdade de Direito da Universidade de Lisboa, 11 e 13 jan. 2011. Disponível em: http://www.fd.ulisboa.pt/wpcontent/uploads/2014/12/Alexandrino-Jose-de-Melo-Hermeneutica-dos-DireitosHumanos.pdf. Acesso em: 23 abr. 2020.

ALVARENGA, Rubia Zanotelli de. Hermenêutica Jurídica e Direitos Humanos Sociais do Trabalhador. In: Raízes Jurídicas, v. 4, n. 2, jul./dez. 2008. Disponível em: https://juslaboris.tst.jus.br/handle/20.500.12178/80945. Acesso em 25 abr. 2020. 
DIMOULIS, Dimitri; MARTINS, Leonardo. Teoria Geral dos Direitos Fundamentais. 5. ed. rev., atual. e ampl. São Paulo: Atlas, 2014.

GORZONI, Paula Fernanda Alves da Cunha. Supremo Tribunal Federal e a vinculação dos direitos fundamentas nas relações entre particulares. 2007. Monografia (Direito Público). Sociedade Brasileira de Direito Público - SBDP. Escola de Formação. São Paulo. 2007.

LEAL, Mônia Clarissa Hennig. Corte Interamericana de Direitos Humanos e Jurisdição Constitucional: judicialização e ativismo judicial em face da proteção dos direitos humanos e fundamentais? In: Revista de Investigações Constitucionais, Curitiba, vol. 1, n. 3, set./dez. 2014. Disponível em: https://revistas.ufpr.br/rinc/article/view/40518. Acesso em: 14 abr. 2020.

MAGALHÃES, Davi Araújo; DUTRA, Graciele Neto Cardoso Lins. O Direito ao Esquecimento - Eficácia Horizontal dos Direitos Fundamentais no âmbito virtual. Disponível em:

http://nippromove.hospedagemdesites.ws/anais_simposio/arquivos_up/documentos/artigos/0a d6a905918c1bab3d9f2c2f3fa9b747.pdf. Acesso em: 23 abr. 2020.

MARRAFON, Marco Aurélio; ROBI FILHO, Ilton Norberto. Constituição e Efetividade dos Direitos Fundamentais: caminhos para superação da perspectiva tradicional do direito constitucional brasileiro a partir do princípio da factibilidade e do desenvolvimentismo. In: Constituição, Economia e Desenvolvimento: Revista da Academia Brasileira de Direito Constitucional, Curitiba, 2014, vol. 6, n. 11, p. 284, jul./dez. 2014. Disponível em: http://www.abdconst.com.br/revista12/constituicaoMarcoIlton.pdf. Acesso em: 14 abr. 2020.

MAUÉS, Antonio Moreira. Supralegalidade dos tratados internacionais de direitos humanos e interpretação constitucional. In: Revista Internacional de Direitos Humanos, 2013. Disponível em: http://www.corteidh.or.cr/tablas/r32493.pdf. Acesso em: 14 abr. 2020.

MELLO, Marcos Bernardes de. Teoria do Fato Jurídico. Plano da Existência. 18. ed. São Paulo: Saraiva, 2012.

MELlO, Marcos Bernardes de. Teoria do Fato Jurídico - Plano de Eficácia. $1^{a}$ parte. 10. ed. São Paulo: Saraiva, 2015. [Livro Digital].

MORAES, Alexandre de. Direito Constitucional. 33. ed. rev. e atual. São Paulo: Atlas, 2017.

PIOVESAN, Flávia. A Constituição Brasileira de 1988 e os Tratados Internacionais de Proteção dos Direitos Humanos. 2017. Disponível em:

https://ww2.stj.jus.br/publicacaoinstitucional/index.php/API/article/download/.../3638.

Acesso em: 25 abr. 2020.

PIOVESAN, Flávia. Direitos Humanos e o direito constitucional internacional. 14. ed. rev. e atual. São Paulo: Saraiva, 2013. 
DA (IM)POSSIBILIDADE DE EFICÁCIA HORIZONTAL DOS DIREITOS FUNDAMENTAIS NA ESFERA INTERNACIONAL: A EFICÁCIA DOS DIREITOS FUNDAMENTAIS NAS RELAÇÕES ENTRE PARTICULARES NO SISTEMA INTERAMERICANO DE PROTEÇÃO AOS DIREITOS HUMANOS

PIOVESAN, Flavia. Tratados Internacionais de Proteção aos Direitos Humanos: jurisprudência do STF. 2008. Disponível em: www.oas.org/es/sadye/inclusionsocial/protocolo-ssv/docs/piovesan-tratados.pdf. Acesso em: 24 abr. 2020.

REISSENGER, Simone. Reflexões sobre a efetividade dos direitos fundamentais sociais. In: XV CONPEDI, Manaus, 2006. Disponível em: http://www.publicadireito.com.br/conpedi/manaus/arquivos/anais/bh/simone_reissinger.pdf. Acesso em: 24 abr. 2020.

REZEK, Francisco. Direito Internacional Público. 10. ed. São Paulo: Saraiva, 2005.

ROCHA, Cármen Lúcia Antunes. O constitucionalismo contemporâneo e a instrumentalização para a eficácia dos direitos fundamentais. In: Revista CEJ, v. 1, n. 3, set./dez. 1997. Disponível em:

http://www.jf.jus.br/ojs2/index.php/revcej/article/viewArticle/116/159. Acesso em: 25 abr. 2020 .

RODRIGUES, Leandro Nascimento; LEAL, Pastora do Socorro Teixeira. A eficácia dos direitos fundamentais nas relações privadas à luz da jurisprudência do Supremo Tribunal Federal: análise crítica do Recurso Especial 201.819-8 e Ação Direta de Inconstitucionalidade 4815. Revista Direitos e Garantias Fundamentais, Vitória/ES, v. 19, n. 2. maio/ago. 2018. Disponível em: http://sisbib.emnuvens.com.br/direitosegarantias/article/view/1085. Acesso em: 25 abr. 2020.

SARLET, Ingo Wolfgang. A eficácia dos direitos fundamentais: uma teoria geral dos direitos fundamentais na perspectiva constitucional. 11. ed. rev. atual. Porto Alegre: Livraria do Advogado, 2012.

SARMENTO, Daniel. Direitos Fundamentais e Relações Privadas. 2. ed. Rio de Janeiro: Editora Lumen Juris, 2010.

SETTI, Bruna Migliaccio; LIMA, Jairo Néia. Eficácia Horizontal dos Tratados Internacionais de Direitos Humanos à Luz do Sistema Interamericano. Disponível em: http://publicadireito.com.br/publicacao/ufpb/livro.php?gt=196. Acesso em: 14 abr. 2020.

VIEGAS, Cláudia Mara de Almeida Rabelo; NASCIMENTO, Uelton David do. A Eficácia Horizontal dos Direitos Fundamentais às Relações Privadas. Disponível em:

http://uniesp.edu.br/sites/_biblioteca/revistas/20170728105436.pdf. Acesso em: 24 abr. 2020.

ZAMORANO, Fernanda Raso. Um olhar sobre a eficácia dos direitos fundamentais nas relações entre particulares. Observatório da Jurisdição Constitucional, Instituto Brasiliense de Direito Público, ano 7, n. 2, jul./dez. 2014. Disponível em:

https://www.portaldeperiodicos.idp.edu.br/observatorio/article/view/995. Acesso em: 14 abr. 2020. 